\title{
Viral Hepatitis B and C Detection among Ebola Survivors and Health Care Workers in Makeni, Sierra Leone
}

\author{
Nadege Goumkwa Mafopa1,2*, Marta Giovanetti ${ }^{3}$, Raoul Emeric Guetiya Wadoum ${ }^{4}$, \\ Antonella Minutolo², Claude Kwe Yinda ${ }^{5}$, Gianluca Russo6, Béatrice Dambaya7, Georges Teto ${ }^{7}$, \\ Georgia Ambada7, Patrick Turay8, Judith Torimiro' ${ }^{1,9}$, Alexis Ndjolo1,9, Vittorio Colizzi², \\ Carla Montesano $^{2 *}$
}

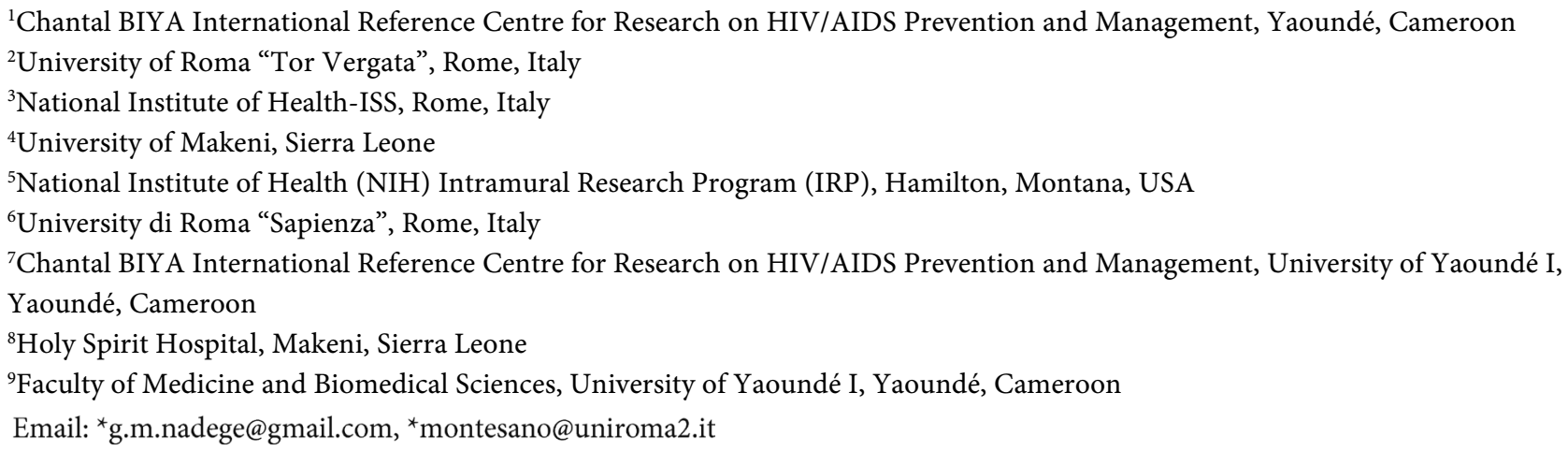

How to cite this paper: Mafopa, N.G., Giovanetti, M., Wadoum, R.E.G., Minutolo, A., Yinda, C.K., Russo, G., Dambaya, B., Teto, G., Ambada, G., Turay, P., Torimiro, J., Ndjolo, A., Colizzi, V. and Montesano, C. (2020) Viral Hepatitis B and C Detection among Ebola Survivors and Health Care Workers in Makeni, Sierra Leone. Journal of Biosciences and Medicines, 8, 18-32. https://doi.org/10.4236/jbm.2020.810003

Received: August 17, 2020

Accepted: October 6, 2020

Published: October 9, 2020

Copyright $\odot 2020$ by author(s) and Scientific Research Publishing Inc. This work is licensed under the Creative Commons Attribution International License (CC BY 4.0).

http://creativecommons.org/licenses/by/4.0/ (c) (i) Open Access

\begin{abstract}
Viral hepatitis B and C infections are among the leading cause of death in Sub-Saharan Africa. Lack of knowledge and awareness in the general population as in health care settings may enhance the propagation of these diseases. We aimed at determining the prevalence of HBV and HCV in Ebola survivors and health care workers (HCWs) of the Makeni town in Sierra Leone. We conducted a cross-sectional study during the last 2013-2016 Ebola outbreak in Makeni among Ebola survivors $(N=68)$ and 81 Health care workers from Holy Spirit hospital and Loreto clinic, two health care facilities in Makeni district. Serological markers of $\mathrm{HBV}$ ( $\mathrm{HBs} \mathrm{Ag}$, anti-HBs $\mathrm{Ab}$ and anti-HBc $\mathrm{Ab}$ ) and anti-HCV antibodies detection were done using ELISA techniques. The positive detection rates for $\mathrm{HBs} \mathrm{Ag}$, anti-HBs $\mathrm{Ab}$ and anti-HBc antibodies in Ebola survivors were $23.53 \%$ (16/68), 32.35\% (22/68) and 88.89\% (16/18) respectively. Survivors with a current $\mathrm{HBV}$ infection had a positive rate of $38.89 \%(7 / 18)$ and $16.66 \%(3 / 18)$ of them were considered immune due to past HBV infection. HCV prevalence was $26.47 \%$ (18/68) and about $10.29 \%$ (7/68) were HBV/HCV co-infected. The positive detection rates of HBsAg,
\end{abstract}


anti-HBs $\mathrm{Ab}$ and anti-HBc $\mathrm{Ab}$ were 37.07\% (30/81), 33.33\% (27/81) and $30.86 \%(25 / 81)$ respectively in health care workers. We observed that $4.94 \%$ (4/81) of the HCWs were currently infected with HBV. Participants considered as immune due to past infection represented $23.47 \%(19 / 81)$ and those immune due to vaccination represented $2.47 \%(2 / 81)$. The prevalence of HCV infection among health staff was $2.47 \%$ (2/81) with $1.23 \%$ (1/81) being $\mathrm{HBV} / \mathrm{HCV}$ co-infection. Our findings showed that viral hepatitis infection is a burden for Sierra Leone government. There is an urgent need to develop and implement strategies that could improve population immunization against $\mathrm{HBV}$ and vulgarization of $\mathrm{HCV}$ treatment programs.

\section{Keywords}

Viral Hepatitis B and C, Ebola Survivors, Health Care Workers

\section{Introduction}

World Health Organization reports that mortality due to viral hepatitis has increased by $63 \%$ since the years 1990 and is now ranked the seventh leading cause of mortality worldwide. Viral hepatitis is responsible for approximately 1.34 million deaths yearly in the world. It is reported worldwide that hepatitis B virus (HBV) and hepatitis $\mathrm{C}$ virus (HCV) account for the most viral hepatitis morbidity and mortality infections, with Sub-Saharan Africa bearing a substantial portion of the global burden of these infections. Despite the untold burden, a detailed epidemiology and understanding of the disease have not been documented [1].

Reports state that the global HCV seroprevalence is between $2 \%$ and $3 \%$, with an estimated of 71.1 million patients with active viraemia. A recent meta-analysis suggested an overall HCV seroprevalence of $2.98 \%$ in Sub-Saharan Africa [2] [3]. In 2002, Valsa and collaborators [4] reported that central African region has the highest estimated prevalence of 6\%; West Africa has an estimated prevalence of $2.4 \%$, and southern and east Africa with the lowest estimated prevalence of $1.6 \%$.

Hepatitis B is a global health menace, with an estimated of 257 million people chronically hepatitis B surface antigen (HBsAg) positive [5]. Although hepatitis $B$ is an entirely vaccine-preventable disease and effective vaccines being available since 1982, the burden of chronic hepatitis B is increasing annually [1]. According to the 2017 WHO Global Hepatitis Report, the number of HBsAg-positive was the highest in the WHO Western Pacific region and African region, which together accounted for $68 \%$ of the global threat.

Hepatitis B virus is a small DNA virus, a member of the Hepadnaviridae family, with unusual features similar to retroviruses. Its genome is a partially double-stranded circular DNA of about 3.2 kilo base pairs [6]. This virus replicates through an RNA intermediate and can integrate into the host genome. The unique features of the HBV replication cycle confer a distinct ability of the virus 
to persist in infected cells [7]. HBV infection leads to a wide spectrum of liver disease ranging from acute to chronic hepatitis, cirrhosis, and hepatocellular carcinoma [8]. Acute HBV infection can be either asymptomatic or present with symptomatic acute hepatitis. Most adults infected with the virus recover, but 5\% - $10 \%$ are unable to clear the virus and become chronically infected [9].

According to research studies, HCV is a virus of the Flaviviridae family, genus Hepacivirus, with linear single-stranded ribonucleic acid (RNA) genome, positive polarity and approximately 9.5 kilo base paires [10]. The process of interaction between the hepatitis $C$ virus and the host results in elimination of the virus or establishment of chronic infection. Chronic HCV infection occurs in $50 \%$ to $80 \%$ of infected individuals, the inability of the immune system to eliminate the virus is poorly elucidated. It is known that the host immune system, which responds by activating cellular and humoral mechanisms when interacting with the virus, may be insufficient to eradicate the infection [11]. Spontaneous viral clearance and the development of persistent infection are not well defined, but studies with genetic association revealed the importance of genes related to immunity in the susceptibility and progression of pathogenesis [12].

Sierra Leone, as one of the least developed countries in the world with weak healthcare systems, crucial lack of qualified human and infrastructural resources is one of the endemic country in Western Africa [13]. Several studies on HBV and HCV have been conducted in this country among various population groups. The study conducted among primary school children, in 1998 by Hodges et al., [14] detected HBsAg in $18 \%$ of the children tested. Another study among pregnant women of middle and high socio-economic class in Sierra Leone showed a $6.2 \%$ seroprevalence of hepatitis B [15]. Recently, a study screening blood donor candidates for blood-borne pathogens found an HBsAg prevalence of $15 \%$ in men and $13 \%$ in women from a single hospital in Tonkolili Province, Sierra Leone. Data of the study conducted in the Tonkolili province on HCV showed a prevalence of $8 \%$ in men and $7 \%$ in women [16], of which $0.22 \%$ was suspected Ebola cases of the 2013-2016 outbreak [17]. These findings illustrate the serious public health risks that viral hepatitis pose in Sierra Leone.

Healthcare workers (HCWs) are considered a high-risk group for infectious diseases due to occupational exposure to blood-borne pathogens. Previous studies in Africa found high HBV infection and exposure rates (roughly 10\%) in HCWs in South Africa, Nigeria and even in some town of Sierra Leone. Worldwide, approximately 2 million HCWs are infected with HBV through sharp injury [18] [19] [20]. The phenomenon of blood borne infection among health staff has also been observed during the last EBOV epidemic where Sierra Leone recorded the highest burden with 14,124 reported cases and 3956 confirmed deaths [21]. Globally, the West Africa outbreak registered about 881 cases of infection among health care workers with 513 deaths (that is $58.23 \%$ of mortality) [22]. Thus, the percentage of HCWs infected was $1.45 \%$ in Guinea, $8.07 \%$ in Liberia, and $6.85 \%$ in Sierra Leone [23]. Clarifying the prevalence of other infectious diseases such as viral hepatitis B and C could help improve biological fol- 
low up of EVD survivors. In addition, having an idea on the prevalence of HBV and HCV markers in HCWs as well as assessing their awareness could help to establish preventive measures. This will go a long way to minimise the potentially devastating health consequences in the near future in Sierra Leone.

\section{Methods}

\section{Study area and Sample population}

A cross-sectional study was conducted during the last 2013-2016 Ebola outbreak in Makeni from April to November 2015. Makeni, capital of the Bombali District of Sierra Leone, experienced 1050 confirmed EBOV cases during this outbreak [24].

We determined the required sample size as described by Lwanga and Lemeshow (1991) [25] in their practical manual on "Sample size determination in Health studies". Below is the formula for calculation:

$$
N=Z_{1-\alpha / 2}^{2}\left(1-p / \varepsilon^{2} \cdot p\right)
$$

$N=$ required sample size.

$Z_{1-\alpha / 2}^{2}=$ the confident level at $95 \%$ and is equal to 1.96 .

$P=$ the estimated prevalence of HBV in Sierra Leone $(p=15.5 \%)$ [15].

$\mathcal{E}=$ relative precision equal to 0.15 .

After calculation, we obtained a required sample size of 71 .

We chose to use the prevalence of HBV due to the fact that Sierra Leone is more endemic to HBV than HCV.

Ebola survivors were enrolled at Loreto clinic, which was the health unit designated for their biological follow-up. The Loreto clinic and Holy Spirit hospital were our partners within the framework of implementing routine health care service for Ebola survivors and HCWs living in areas with poor medical coverage during the outbreak. For the implementation to be effective, we launched serosurvey studies within local communities. As far as this piece of work is concerned, we intended to have a picture of viral hepatitis in our environment while working.

Our overall sample size was 149 samples collected mainly from health staff and Ebola survivors. About 81 Health care workers from Holy Spirit hospital and Loreto clinic, two health care facilities in Makeni district were enrolled in this study. Ebola survivors $(N=68)$ from the surrounding rural areas follow up at the Loreto clinic were also enrolled. For Ebola survivors, the inclusion criteria was to be a person who was infected by Ebola virus, presented signs and symptoms of the disease, tested Ebola positive by real time polymerase chain reaction and later on recovered. For health staff the inclusion criteria was individual who works in health care services. This includes clinical staff (physicians, nurses and laboratory staff), administrative workers in the hospital or health centre, including cleaners, drivers, security personnel and community health workers. The Ethical Review Board of the Ministry of Health and Sanitation of Sierra Leone approved this study and participants gave their approval by signing or finger- 
printing a written consent form. Although working in emergency state of Ebola outbreak, we designed a questionnaire form and verbally administered it to participants. Especially for HCWs, demographic data and information about knowledge, awareness and clinical history of $\mathrm{HBV}$ and HCV were collected using this questionnaire before obtaining $4 \mathrm{ml}$ of peripheral blood by venepuncture. Data related to sex, age and educational level of Ebola survivors were taken from the questionnaire used in our previous study on "Seroprevalence of Ebola virus infection in Bombali District, Sierra Leone" [26].

Laboratory detection of hepatitis $C$ virus

Serological assays were performed to detect antibodies against hepatitis $\mathrm{C}$ virus using ELISA technique as described by ELISA kits from Delta Biologicals S.r.l. Subsidiary of ERBA Diagnostics, INC Roma-Italy. The results were presented and reported as positive or negative following the manufacturer instructions.

\section{Laboratory detection of hepatitis $B$ virus}

ELISA technique as described by using ELISA kits from Delta Biologicals S.r.l. Subsidiary of ERBA Diagnostics, INC Roma-Italy was used to detect three HBV markers including $\mathrm{HBsAg}$ antigen, anti-HBs and anti- $\mathrm{HBc}$ antibodies. Results were interpreted and reported as positive or negative based on manufacturer instructions.

Statistical analysis

Data were collected and entered in a customized template in EpiData software version 3.1. Statistical analyses were done using both Microsoft Excel 2016 and GraphPad Prism 7.04. $p<0.05$ was considered statistically significant.

\section{Results}

\section{Demographic data of EBOV survivors}

We defined an Ebola virus disease survivor here as a person who was infected by Ebola virus, presented signs and symptoms of the disease and later on recovered. The median age of Ebola survivors who were enrolled in this study was 30 years [IQR: 18 - 38] (Range: 2 to 65). Female participants were more represented (54.41\%; 37/68) with a median age of 35 years [IQR: 23 - 45]. Male participants constituted about $45.59 \%$ (31/68) with a median age of 25 years [IQR: 15.5 30.75]. Among survivors, 47.05\% (32/68) have never gone to school, $54.41 \%$ (37/68) have once gone to school. Their educational level varied from attending primary school $24.32 \%$ (9/37), secondary school $27.02 \%(10 / 37)$ and university $2.70 \%$ (1/37). Surprisingly, $47.94 \%$ (17/37) were unable to remember the level of their education. Farming and trading were reported as the major occupation of these participants and the other one were just struggling to have something to do. We did not have any information on their knowledge of viral hepatitis infections.

$H B V$ and $H C V$ seroprevalence in $E B O V$ survivors

Prevalence of $H B V$ serologic markers among EVD survivors 
We search for three HBV serologic markers (HBs Ag, anti-HBs Ab and anti-HBc $\mathrm{Ab}$ ) among the $68 \mathrm{EVD}$ survivors. The positive detection rates of each marker was $23.53 \%$ (16/68), $32.35 \%$ (22/68) and $88.89 \%$ (only 16/18) respectively (Table 1$)$. There was no statistical difference $(p=0.2247)$ between the proportions of $\mathrm{HBs} \mathrm{Ag}^{+}$and anti-HBs $\mathrm{Ab}^{+}$survivors. However, we observed a statistical difference $(p<0.0001)$ between the previous mentioned proportions and the proportion of anti-HBc $\mathrm{Ab}^{+}$cases.

Only 18 survivor samples were analysed for anti- $\mathrm{HBc}$ Ab detection. We assessed the seroprevalence of current HBV infection (HBs Ag positive and anti- $\mathrm{HBc} \mathrm{Ab}$ positive) and we recorded a prevalence of up to $38.89 \%$ (7/18). About $16.66 \%(3 / 18)$ of EBOV survivors were considered immune due to past infection (HBs Ag negative, anti- $\mathrm{HBc} \mathrm{Ab}$ positive and anti-HBs Ab positive). We did not observe any statistical difference between these two groups ( $p=0.1421)$.

\section{Prevalence of HCV among EVD survivors}

The positive rate of anti-HCV antibodies detection in EBOV survivor participants was $26.47 \%$ (18/68). We had about $10.29 \%$ (7/68) of HBV/HCV co-infection among Ebola survivors.

Our findings did not show any statistical difference $(p=0.64)$ between the proportion of survivors infected by HCV and the proportion infected by HBV.

Demographic data of Health care workers

We defined HCWs as individuals who work in health services as described above in the methodology. We enrolled for this study 81 health care workers with a median age of 39 years [IQR: 30 - 45] (Range: 20 - 71). Male proportion $56.79 \%(46 / 81)$ was higher than female $43.21 \%(35 / 81)$ with sex ratio of 1.3 in favour of men. Their median age was 40 [IQR: 31 - 45] and 35 [IQR: 27 - 47] years respectively. Working experience varied from newly recruited to more than 20 years with the majority having a working experience between 0 to 5 years $39.50 \%(32 / 81)$.

Table 1. HBV markers positive frequency among EVD survivors.

\begin{tabular}{|c|c|c|}
\hline HBV markers & Positive proportion (\%) & $p$ value at $95 \% \mathrm{CI}$ \\
\hline \multirow{3}{*}{ HBs $A g$} & $23.53 \%(16 / 68)$ & \multirow{5}{*}{$p=0.2247$} \\
\hline & $n=68$ & \\
\hline & & \\
\hline \multirow{2}{*}{ Anti-HBs $A b$} & $32.35 \%(22 / 68)$ & \\
\hline & $n=68$ & \\
\hline \multirow{3}{*}{$A n t i-H B c A b$} & $88.89 \%(16 / 18)$ & \multirow{5}{*}{$p<0.0001$} \\
\hline & $n=18$ & \\
\hline & & \\
\hline \multirow{2}{*}{$H B s A^{+}$Anti-HBs $A b$} & $55.88 \%(38 / 68)$ & \\
\hline & $n=68$ & \\
\hline$H B s A^{+}$Anti-HBc $A b^{+}$ & $38.89 \%(7 / 18)$ & \multirow{4}{*}{$p=0.1421$} \\
\hline Current infection & $n=18$ & \\
\hline$H B s A^{-}$Anti-HBs $A b^{+} A n t i-H B c A b^{+}$ & $16.66 \%(3 / 18)$ & \\
\hline Immune due to past infection & $n=18$ & \\
\hline
\end{tabular}

( $n=$ number of tested sample), $p<0.05$ was considered statistically significant. 
Health care workers awareness about $H B V$ and $H C V$

As described in Figure 1, a high proportion of health workers $64.19 \%(52 / 81)$ knew about the existence of HBV virus infection whereas $30.86 \%(25 / 81)$ have never heard about this infectious disease and 4.94\% (3/81) did not give an information.

On the other hand, about $49.38 \%(40 / 81)$ of health care workers knew that there is an infectious disease caused by hepatitis c virus, while $14.81 \%(12 / 81)$ have never heard about HCV infection and $35.80 \%$ (29/81) have no information.

There wasn't a statistical difference $(p=0.06)$ between the proportion of participants having HBV knowledge and those with HCV knowledge among HCWs.

\section{Health staff knowledge about $H B V$ and HCV serological status}

Only $28.39 \%$ (23/81) of health care workers have been screened for HBV infection of which $69.56 \%(16 / 23)$ could remember the date of their screening. The majority of these health staff $65.43 \%$ (53/81) had never been diagnosed for HBV infection and $6.17 \%(5 / 81)$ were unable to give any information about their serologic status. There was a significant difference $(p<0.0001)$ between the proportion of health staff knowing their HBV serologic status. For hepatitis C infection, $17.28 \%$ (14/81) of participants knew about their status, $74.07 \%(60 / 81)$ have never been tested and $8.64 \%$ (7/81) could not inform us of their serologic status (Figure 2). We observed a significant difference $(p<0.0001)$ between the proportion of health staff knowing their HCV serologic status.

The proportion of health staff knowing their HBV status wasn't statistically different $(p=0.09)$ from the proportion of staff with HCV status knowledge.

Awareness of $H B V$ vaccine

We observed in this study that $53.09 \%(43 / 81)$ of health care workers had knowledge on the existence of a vaccine against HBV infection, 41.97\% (34/81) did not know that there is a preventive vaccine against HBV and $4.94 \%(4 / 81)$ did not inform us (Figure 3 ). Only $6.17 \%$ (5/81) of participants had been vaccinated whereas $93.82 \%$ have never received a single dose vaccine $(p<0.0001)$.

Knowledge on $H B V$ and $H C V$ treatment

Less than $50 \%$ of health care workers in Makeni, Sierra Leone were aware that there are anti-viral treatments for HCV and HBV infectious diseases (Figure 4).

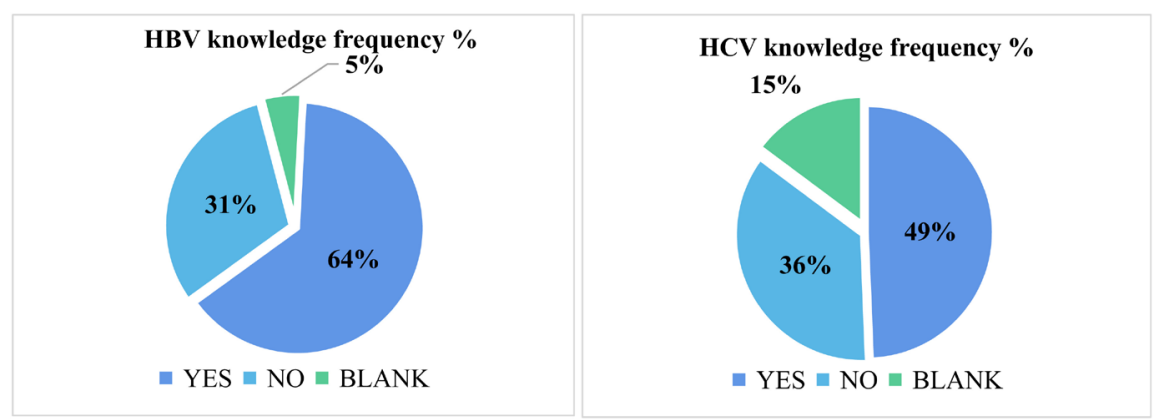

Figure 1. Health care workers knowledge frequency on the existence of hepatitis $\mathrm{B} /$ hepatitis $\mathrm{C}$ virus infections. Blank = Information not available. 


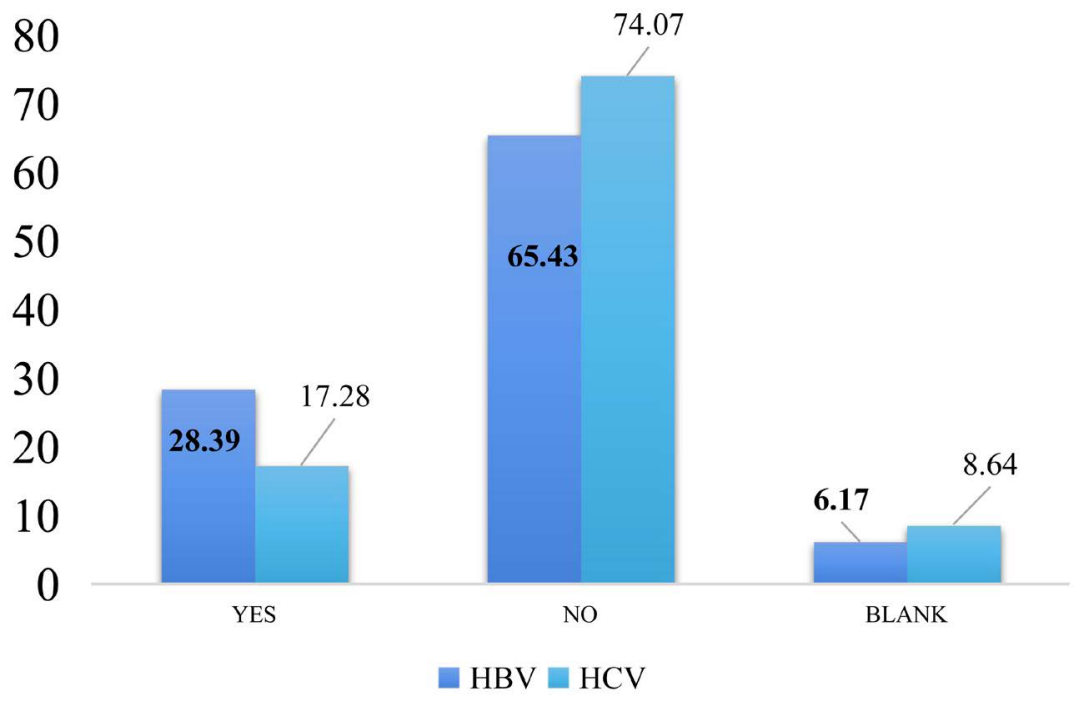

Figure 2. Proportion (\%) of awareness on serologic status. Blank = Information not available; $\left.{ }^{*}\right): p<0.0001$ between HCWs knowing their HBV status and those not knowing; $\left.{ }^{* *}\right): p<0.0001$ between HCWs knowing their HCV status and those not knowing.

\section{PROPORTION \%}

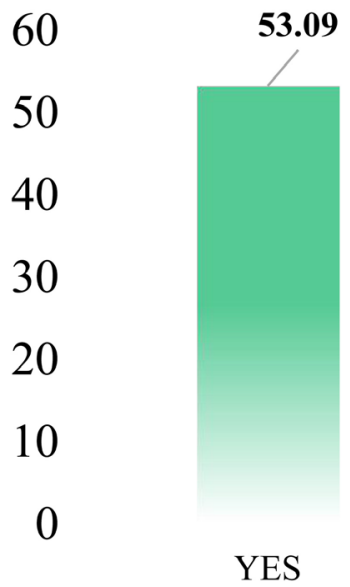

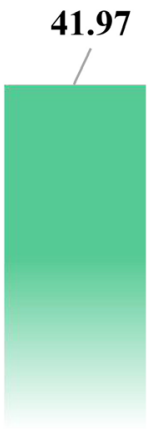

NO

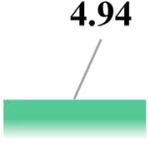

BLANK

Vaccine knowledge

Figure 3. Knowledge on HBV preventive vaccine. Blank = Information not available.

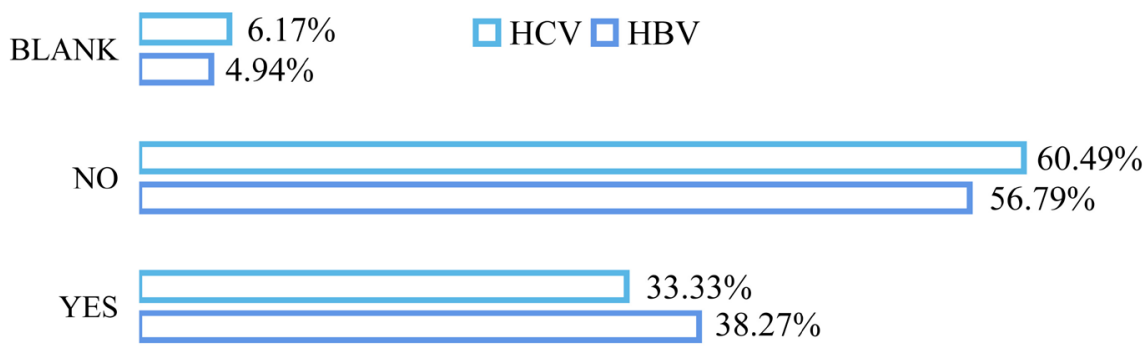

\section{Proportions (\%)}

Figure 4. Treatment awareness among health care workers. Blank = Information not available. 
Knowledge on $H B V$ and $H C V$ route of transmission

Participant responses revealed that $58.33 \%$ and $50.36 \%$ of health care workers had an average knowledge on transmission routes of $\mathrm{HBV}$ and HCV respectively as represented in Table 2.

Prevalence of HBV serologic markers and HCV among health care workers

Of the 81 health care workers the positive detection rates of $\mathrm{HBs} \mathrm{Ag}$, anti-HBs $\mathrm{Ab}$ and anti-HBc Ab were 37.07\% (30/81), 33.33\% (27/81) and 30.86\% (25/81) respectively. Our data revealed that 4/81 (4.94\%) of the HCWs could be doing current $\mathrm{HBV}$ infection (HBs Ag positive and anti-HBc Ab positive). Participants considered as immune due to past infection represented $23.47 \%$ (19/81) and those immune due to vaccination against $\mathrm{HBV}$ infection represented $2.47 \%$ (2/81) with $p=0.0001$ (Table 3).

The prevalence of $\mathrm{HCV}$ infection among health care workers was $2.47 \%$ (2/81). We found HBV/HCV co-infection rate of $1.23 \%$ (1/81).

The proportion of health staff infected with HBV differs significantly $(p<$ 0.0001 ) from the proportion infected by HCV.

$H C W s$ susceptibility to $H B V$ infection related to work experience

Only $90.12 \%$ (73/81) health staff gave us the number of years spend in service. This information was not available for $9.88 \%(8 / 81)$ of them. Table 4 shows that health staff with less than 10 years working experience were more exposed or sus-

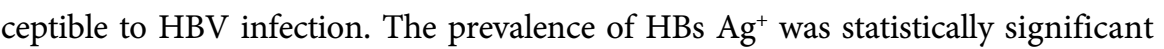

Table 2. Response of participants to hepatitis B and C transmission routes knowledge.

\begin{tabular}{cccccccccccccc}
\hline & \multicolumn{3}{c}{ Sex } & \multicolumn{4}{c}{ Blood } & \multicolumn{3}{c}{ MTCT } & & \multicolumn{2}{c}{ Saliva } \\
\cline { 2 - 13 }$y$ & yes & no & blank & yes & no & blank & yes & no & blank & yes & no & blank \\
\hline HBV & $50 / 81$ & $27 / 81$ & $4 / 81$ & $48 / 81$ & $29 / 81$ & $4 / 81$ & $46 / 81$ & $30 / 81$ & $5 / 81$ & $55 / 81$ & $31 / 81$ & $5 / 81$ \\
$\%$ & 61.73 & 33.33 & 4.94 & 59.25 & 35.80 & 4.94 & 56.79 & 37.04 & 6.17 & 55.55 & 38.27 & 6.17 \\
$H C V$ & $43 / 81$ & $34 / 81$ & $4 / 81$ & $42 / 81$ & $35 / 81$ & $4 / 81$ & $38 / 81$ & $39 / 81$ & $4 / 81$ & & & \\
$\%$ & 53.09 & 41.97 & 4.94 & 51.85 & 43.21 & 4.94 & 46.15 & 48.15 & 4.94 & & & \\
\hline
\end{tabular}

MTCT $=$ Mother to child transmission; Blank = Information not available .

Table 3. HBV markers positive frequency among HCWs.

\begin{tabular}{|c|c|c|}
\hline HBV markers (HCWs) & Positive proportion $(\%)(n=81)$ & $p$ value at $95 \%$ CI \\
\hline$H B s A g$ & $37.04 \%(30 / 81)$ & \\
\hline Anti-HBs $A b$ & $33.3 \%(27 / 81)$ & Not significant \\
\hline$A n t i-H B c A b$ & $30.86 \%(25 / 81)$ & \\
\hline $\begin{array}{c}H B s \mathrm{Ag}^{+} \text {anti-HBc } A b^{+} \\
\text {Current infection }\end{array}$ & $4.94 \%(4 / 81)$ & \\
\hline $\begin{array}{c}H B s \mathrm{Ag} \text {, Anti-HBs } A b^{+} \text {and anti-HBc } A b^{+} \\
\text {Immune due to past infection } \\
\text { Only anti-HBs } A b^{+} \\
\text {Immune due to vaccine }\end{array}$ & $23.47 \%(19 / 81)$ & $p=0.0001$ \\
\hline
\end{tabular}

( $n=$ number of tested sample), $p<0.05$ was considered statistically significant. 
Table 4. Prevalence of HBV markers by number of years in service.

\begin{tabular}{ccccc}
\hline \multirow{2}{*}{$\begin{array}{c}\text { Working experience } \\
\text { (Years) }\end{array}$} & \multicolumn{3}{c}{ HBV markers $n(\%)$} & \multirow{2}{*}{$\boldsymbol{p \text { value }}$} \\
\cline { 2 - 4 } & $H B s \mathrm{Ag}^{+}$ & Anti-HBs $A b^{+}$ & Anti-HBc $A b^{+}$ & \\
\hline$\leq 10$ & $44.44 \%(24 / 54)$ & $23.33 \%(12 / 54)$ & $23.33 \%(12 / 54)$ & $p=0.0211$ \\
$>10$ & $26.32 \%(5 / 19)$ & $42.11 \%(8 / 19)$ & $47.37 \%(9 / 19)$ & not significant \\
\hline
\end{tabular}

( $n=$ number of tested sample), $p<0.05$ was considered statistically significant.

$(p=0.0211)$ compare to the prevalence of anti- $\mathrm{HBs} \mathrm{Ab}^{+}$and anti- $\mathrm{HBc} \mathrm{Ab}^{+}$respectively.

\section{Discussion}

Findings issued from our study showed a prevalence of HBs Ag positive of 23.53\% among Ebola survivors. The positive rate of HCV antibodies detection in these participants was $26.47 \%$ with about $10.29 \%$ of $\mathrm{HBV} / \mathrm{HCV}$ co-infection. These data show the necessity to screen other infections while following patients affected during epidemic outbreak. We observed that about $88.89 \%(16 / 18)$ of Ebola survivors developed antibodies against hepatitis B core, which appears at the onset of symptoms in acute hepatitis B and persists for life. The presence of anti-HBc antibodies indicates previous or ongoing infection with hepatitis B virus in an undefined period [27]. In addition, this elevated proportion of $\mathrm{HBc}$ antibody maker is indicative of the endemicity of Sierra Leone to viral hepatitis B infection. Thus, understanding HBV transmission dynamic within local communities in Sierra Leone is capital for establishment of prevention plan following WHO guidelines.

In spite of all the efforts the government and stakeholders have been putting together to rebuild the educational system that was also seriously destroyed by the civil war; only $54.41 \%$ Ebola survivors have once gone to school implying that this system is still very weak.

It is known that healthcare settings have played a major role in propagation of infectious diseases. As we stated before, healthcare workers (HCWs) are considered a high-risk group for infectious diseases due to occupational exposure to blood-borne pathogens. Knowledge of viral hepatitis among healthcare workers of the Makeni district in Sierra Leone remain problematic although the results of this study revealed that approximately $64.19 \%$ and $49.38 \%$ were informed of the existence of HBV and HCV virus infections respectively. Only $28.39 \%$ (23/81) of health care workers have been screened for HBV infection and for hepatitis C infection, $17.28 \%$ of participants knew about their status. We observed a significant difference $(p<0.0001)$ between the proportion of health staff knowing their HBV/HCV serologic status. Thus, less than $30 \%$ of health staff in Makeni know their serologic status.

The fact that about $53.09 \%$ (43/81) health staff were aware that there is an effective vaccine against hepatitis $B$ virus infection did not have an impact on their immunization through vaccination. Most of them [23.47\% (19/81)] became 
immune due to natural infection and only $6.17 \%$ of these health staff had received vaccine against HBV $(p=0.0001)$. This vaccinated proportion is relatively high compare to that in HCWs in Ethiopia (5.4\%) [28], and in the Democratic republic of Congo (3.6\%) [29] respectively. On the contrary, this result of vaccinated HCWs in Makeni is low compare to that obtained from HWCs (17.5\%) in Freetown the capital city of Sierra Leone [30] and lower than HBV vaccine intake (79.1\%) among health staff in Accra Ghana [31].

HCV prevalence among health care workers was $2.47 \%(2 / 81)$ with $\mathrm{HBV} / \mathrm{HCV}$ co-infection rate of $1.23 \%(1 / 81)$. The seroprevalence of health staff infected with HBV differs significantly $(p<0.0001)$ from the proportion infected by HCV. May be HCV is less present within local community in Makeni than HBV.

Less than $50 \%$ of participants enrolled were aware that there are anti-viral treatments for HCV and HBV infectious diseases. Thus, the necessity to raise advocacy for the implementation of sensitization specific vaccine and treatment programs in rural area as recommended by WHO.

The prevalence of the surface antigen of $\mathrm{HBV}$ varies from one continent to another and even within the countries of a continent as in the different towns of a country. It is reported that in some countries of West Africa like Nigeria and Burkina Faso, HBs Ag positive rate is higher than 10\% [32] [33]. Serosurvey studies screening HBV infection among health workers have shown that $\mathrm{HBs} \mathrm{Ag}$ positive proportion also varies from one region to another. In this study, we ob-

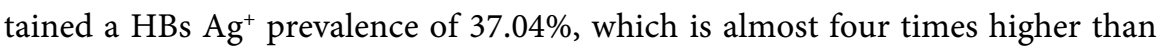
the one obtained by Quin and colleagues [30] in their study conducted among health care worker in Freetown. In addition, our results show a prevalence 30 times higher than data observed in health care workers in a secondary health facility in Lagos State, Nigeria [34]. May be this difference could be because our study was done in rural setting where knowledge and awareness on viral hepatitis is low.

Prior to this study, we conducted a survey to access Ebola diffusion among this health staff and we obtained 3.8\% seroprevalence of anti-EBOV IgG [26]. After performing HBV screening, our results showed that $2.48 \%$ of these HCWs were seropositive to HBV and EBOV. Further investigations revealed that they were one cleaner and one nurse. They might have been affected while performing their duties: the cleaner exposed while managing waste and the nurse while taking care of infected person. Our results also show that health staff with less than 10 years working experience were more exposed or susceptible to HBV infection. We guest this could be due to the fact that they are less experienced in case management. May be their low work experience could be associated with low knowledge and awareness on HBV which could explain their high susceptibility. However, it could be interesting to enlarge the sample size for adequate evaluation of this risk factor.

Although the ministry of health and Sanitation in Sierra Leone has implemented the vaccination program against HBV infection for children less than five years, much is still to be done for the general population and health staff as 
well. The high prevalence of $\mathrm{HBc} A b$ detection among participants of our study is indicative of the threat of viral hepatitis B in Sierra Leone. These results are in line with previous studies that had shown a high prevalence of HBs Ag and current HBV infection among health workers in Freetown [30].

Limitation to this work is that we did not perform the detection of all the five HBV biomarkers that could permit us to outline the different profile in the studied groups. In addition it could have been of great interest to search biochemical parameters like transaminases (Alanine amino-transferase and aspartate amino-transferase).

Another limitation to this study is that we could not assess knowledge and awareness of Ebola survivors as far as viral hepatitis B and C are concerned. In fact, by the time of their enrolment these participants were already frighten by Ebola infection. Raising awareness on viral hepatitis infection among them brought more fear. So we could only ask for their consent to perform HBV and HCV testing on their samples.

\section{Conclusion}

This study was conducted within the framework of implementing routine health care service for Ebola survivors and HCWs living in areas with poor medical coverage. Concretely, the West Africa EBOV outbreak had a great impact on public health service delivery of the affected countries. The management of this epidemic enhanced the establishment of a better surveillance network for other infectious diseases among which viral hepatitis. It is obvious that viral hepatitis infections are really a burden for Sierra Leone government. There is an urgent need to develop and implement strategies that could improve population immunization against HBV. In addition, there is a necessity to raise awareness and establish strategic plans for HCV treatment availability.

\section{Acknowledgements}

The data presented here were obtained with the financial support of the Italian Episcopal Conference (Camillian Task Force), the Italian Cooperation (Dokita ONG) and the Italian Geographical Society (Centro Relazioni con l'Africa).

We also thank the Chantal Biya International Reference Centre for HIV/AIDS Prevention and Management for the technical support.

\section{Conflicts of Interest}

The authors declare no conflicts of interest regarding the publication of this paper.

\section{References}

[1] Spearman, C.W., Mary, A., Reidwaan, A., Betty, A., Yaw, A., Lina, C., Geoffrey, D., Neliswa, G., Chris, K., Michael, K., Philip, L., Olufunmilayo, L., Lohouès-Kouacou, M.J., Papa, S.M., Emmanuel, M., Betty, M., Olusegun, O., John, R., Barbara, S., Abate, B.S., Christian, T. and Mark, W.S. (2017) Hepatitis B in Sub-Saharan Africa: 
Strategies to Achieve the 2030 Elimination Targets. The Lancet Gastroenterology and Hepatology, 2, 900-909. https://doi.org/10.1016/S2468-1253(17)30295-9

[2] Rao, V.B., Johari, N., du Cros, P., Messina, J., Ford, N. and Cooke, G.S. (2015) Hepatitis C Seroprevalence and HIV Co-Infection in Sub-Saharan Africa: A Systematic Review and Meta-Analysis. The Lancet Infectious Disease, 15, 819-824. https://doi.org/10.1016/S1473-3099(15)00006-7

[3] Sonderup, M.W., Mary, A., Reidwaan, A., Betty, A., Yaw, A., Lina, C., Geoffrey, D., Neliswa, G., Marie-Jeanne, L.-K., Phillip, L., Olufunmilayo, L., Papa, S.M., Emmanuel, M., Betty, M., Olesegun, O., John, R., Barbara, S., Abate, B.S., Christian, T., Chris, K. and Spearman, C.W. (2017) Hepatitis C in Sub-Saharan Africa: The Current Status and Recommendations for Achieving Elimination by 2030. The Lancet Gastroenterology and Hepatology, 2, 910-919.

https://doi.org/10.1016/S2468-1253(17)30249-2

[4] Valsa, M., Christine, B. and Ernest, D. (2002) Epidemiology of Chronic Hepatitis C Virus Infection in Sub-Saharan Africa. The Lancet Infectious Diseases, 2, 293-302. https://doi.org/10.1016/S1473-3099(02)00264-5

[5] World Health Organization (2017) Global Hepatitis Report. World Health Organization, Geneva.

https://www.who.int/hepatitis/publications/global-hepatitis-report2017/en/

[6] Gavilanes, F., Gonzales-Ros, A. and Peterson, D. (1982) Structure of Hepatitis B Surface Antigen: Characterization of the Lipid Components and Their Association with the Viral Proteins. Journal of Biological Chemistry, 257, 7770-7777.

[7] Ganem, D. and Schneider, R.J. (2001) Hepadnaviridae and Their Replication. In: Knipe, D.M., Howley, P.M., Griffin, D.E., Martin, M.A., Lamb, R.A., Roizman, B., et al., Eds., Fields Virology, Vol. 4, Lippincott-Raven Publishers, Philadelphia.

[8] Hollinger, F.B. and Liang, T.J. (2001) Hepatitis B Virus. In: Knipe, D.M., Howley, P.M., Griffin, D.E., Lamb, R.A., Martin, M.A., Roizman, B., et al., Eds., Fields Virology, Vol. 4, Lippincott-Raven Publishers, Philadelphia, 2971-3036.

[9] Jake Liang, T. (2009) Hepatitis B: The Virus and Disease. Hepatology, 49, S13-S21. https://doi.org/10.1002/hep.22881

[10] Blackard, J.T., Shata, M.T., Shire, N.J. and Sherman, K.E. (2008) Acute Hepatitis C Virus Infection: A Chronic Problem. Hepatology, 47, 321-331. https://doi.org/10.1002/hep.21902

[11] Chang, K.M. (2003) Immunopathogenesis of Hepatitis C Virus Infection. Clinical Liver Disease, 7, 89-105. https://doi.org/10.1016/S1089-3261(02)00068-5

[12] Da-Silva, N.M.O. and Zanella, R.D.-C. (2016) Hepatitis C: Viral Features and Clinical Aspects. Journal of Prevention and Infection Control, 2, 2. https://doi.org/10.21767/2471-9668.100025

[13] United Nations Development Programme (UNDP) (2013) Human Development Report. The Rise of the South: Human Progress in a Diverse World. UNDP, New York. http://hdr.undp.org/sites/default/files/reports/14/hdr2013 en complete.pdf

[14] Hodges, M., Sanders, E. and Aitken, C. (1998) Seroprevalence of Hepatitis Markers; HAV, HBV, HCV and HEV amongst Primary School Children in Freetown, Sierra Leone. West Africa Journal of Medicine, 17, 36-37.

[15] Wurie, I.M., Wurie, A.T. and Gevao, S.M. (2005) Sero-Prevalence of Hepatitis B Virus among Middle to High Socio-Economic Antenatal Population in Sierra Leone. West Africa Journal of Medicine, 24, 18-20.

https://doi.org/10.4314/wajm.v24i1.28156 
[16] Garcia-Tardon, N., Gresnigt, T.M., Fofanah, A.B. and Grobusch, M.P. (2017) Hepatitis B and C in Tonkolili Province, Sierra Leone. The Lancet, 390, 1485. https://doi.org/10.1016/S0140-6736(17)32390-5

[17] Liu, W.J., et al. (2019) HIV Prevalence in Suspected Ebola Cases during the 2014-2016 Ebola Epidemic in Sierra Leone. Infectious Diseases of Poverty, 8, Article No. 15. https://doi.org/10.1186/s40249-019-0525-9

[18] Sondlane, T.H., Mawela, L., Razwiedani, L.L., Selabe, S.G., Lebelo, R.L., Nare, R.J., et al. (2016) High Prevalence of Active and Occult Hepatitis B Virus Infections in Healthcare Workers from Two Provinces of South Africa. Vaccine, 34, 3835-3839. https://doi.org/10.1016/j.vaccine.2016.05.040

[19] Alese, O.O., Alese, M.O., Ohunakin, A. and Oluyide, P.O. (2016) Seroprevalence of Hepatitis B Surface Antigen and Occupational Risk Factors among Health Care Workers in Ekiti State. Nigeria Journal of Clinical and Diagnostic Research, 10, LC16-LC18. https://doi.org/10.7860/JCDR/2016/15936.7329

[20] Coppola, N., De Pascalis, S., Onorato, L., Calò, F., Sagnelli, C. and Sagnelli, E. (2016) Hepatitis B Virus and Hepatitis C Virus Infection in Healthcare Workers. World Journal of Hepatology, 8, 273-281. https://doi.org/10.4254/wjh.v8.i5.273

[21] Catherine, F.H., Catherine, R.McG., Steve, D., Marc, B., David, A.J.M., David, M., Chrissy, H.R., Alex, K., Dhan, S., Richard, T. and Judith, R.G. (2017) Ebola Exposure, Illness Experience, and Ebola Antibody Prevalence in International Responders to the West African Ebola Epidemic 2014-2016: A Cross-Sectional Study. PLOS Medicine, 14, e1002300. https://doi.org/10.1371/journal.pmed.1002300

[22] David, K.E., Markus, G. and Anna, P. (2015) Health-Care Worker Mortality and the Legacy of the Ebola Epidemic. World Bank, Washington DC.

[23] World Health Organization (2016) Global Health Sector Strategy on Viral Hepatitis 2016-2021. Toward Ending Viral Hepatitis. http://www.who.int/hepatitis/strategy2016-2021/ghss-hep/en

[24] Peter, J.H., Amie, J.E., Tokiko, W., Tadashi, M., Makoto, Y., Satoshi, F., Tammy, A., Isaiah, R., Alhaj, N.J., Gabriele, N., Yoshihiro, K. and Foday, S. (2019) Serological Analysis of Ebola Virus Survivors and Close Contacts in Sierra Leone: A Cross-Sectional Study. PLOS Neglected Tropical Diseases, 13, e0007654.

https://doi.org/10.1371/journal.pntd.0007654

[25] Lwanga, S.K. and Lemeshow, S. (1991) Sample Size Determination in Health Studies: A Practical Manual. World Health Organization, Geneva.

[26] Nadege, G.M., Gianluca, R., Raoul, E.G.W., Emmanuel, I., Vincent, B., Marta, G., Antonella, M., Patrick, T., Thomas, B.T., Brima, K., Massimo, A., Maurizio, M. and Carla, M. (2017) Seroprevalence of Ebola Virus Infection in Bombali District, Sierra Leone. Journal of Public Health in Africa, 8, 732.

[27] Department of Health and Human Services, Centers for Disease Control and Prevention, Division of Viral Hepatitis. Interpretation of Hepatitis B Serologic Test Results. http://www.cdc.gov/hepatitis

[28] Abeje, G. and Azage, M. (2015) Hepatitis B Vaccine Knowledge and Vaccination Status among Health Care Workers of Bahir Dar City Administration, Northwest Ethiopia: A Cross Sectional Study. BMC Infectious Disease, 15, Article No. 30. https://doi.org/10.1186/s12879-015-0756-8

[29] Shindano, T.A., Bahizire, E., Fiasse, R. and Horsmans, Y. (2017) Knowledge, Attitudes, and Practices of Health-Care Workers about Viral Hepatitis B and C in South Kivu. American Journal of Tropical Medicine and Hygiene, 96, 400-404. https://doi.org/10.4269/ajtmh.16-0287 
[30] Qin, Y.-L., Li, B., Zhou, Y.-S., Zhang, X., Li, L., et al. (2018) Prevalence and Associated Knowledge of Hepatitis B Infection among Healthcare Workers in Freetown, Sierra Leone. BMC Infectious Diseases, 18, Article No. 315. https://doi.org/10.1186/s12879-018-3235-1

[31] Gloria, A.A., Kenneth, N.A.O., Ekua, E.H., Afua, A.A., Jerry, S.S., Christian, K.A and Gifty, H.O. (2019) Hepatitis B Vaccine Uptake among Healthcare Workers in a Referral Hospital. Accra Pan African Medical Journal, 33, 96.

[32] Tao, I., Compaore, T.R., Diarra, B., Djigma, F., Zohoncon, T.M., Assih, M., et al. (2014) Seroepidemiology of Hepatitis B and C Viruses in the General Population of Burkina Faso. Hepatitis Research and Treatment, 2014, Article ID: 781843. https://doi.org/10.1155/2014/781843

[33] Musa, B.M., Bussell, S., Borodo, M.M., Samaila, A.A. and Femi, O.L. (2015) Prevalence of Hepatitis B Virus Infection in Nigeria, 2000-2013: A Systematic Review and Meta-Analysis. Nigerian Journal of Clinical Practice, 18, 163-172. https://doi.org/10.4103/1119-3077.151035

[34] Hope, V.D., Eramova, I., Capurro, D. and Donoghoe, M.C. (2014) Prevalence and Estimation of Hepatitis B and C Infections in the WHO European Region: A Review of Data Focusing on the Countries outside the European Union and the European Free Trade Association. Epidemiology and Infections, 142, 270-286.

https://doi.org/10.1017/S0950268813000940 